\title{
Analysis of Multiple Gene Expression Array Experiments after Repetitive Hybridizations on Nylon Membranes
}

BioTechniques 33:108-117(July 2002)

\author{
Jorrit J. Hornberg ${ }^{1}$, Richard \\ R. de Haas ${ }^{2}$, Henk Dekker ${ }^{2}$, \\ and Jan Lankelma ${ }^{1,2}$ \\ 1V U Dept. of Molecular Cell \\ Physiology and ${ }^{2} \mathrm{VU}$ medical \\ center, Amsterdam, The \\ Netherlands
}

\section{INTRODUCTION}

In recent years, gene expression measurements have been carried out on a large scale using both glass microarrays $(7,15)$ and nylon macroarrays (5). Most studies focus on alterations in the gene expression among different tissues, alterations between normal and pathological samples, and differential gene expression occurring during growth or as the result of environmental conditions $(1,4,6,10,12,17-19)$. An advantage of microarrays, apart from the high number of genes screened, is the sensitivity of detection because of the relatively high probe concentration, which is a result of the small incubation volumes used. However, in a comparative study, nylon membranes (referred to here as macroarrays) used in conjunction with ${ }^{33} \mathrm{P}-1 \mathrm{a}-$ beled radioactive probes did not show lower sensitivity, which can be explained by the larger amount of DNA spotted on the membrane (3). Currently, macroarrays are more accessible because they can be applied using standard laboratory equipment. However, a disadvantage of radioactive detection is that only one sample can be analyzed per membrane, yielding variations caused by different amounts of target cDNA when comparing two samples (20). Microarrays on glass slides allow for the direct comparison of two samples on one array because both samples are labeled with different fluorescent probes. This permits an accurate measurement of a 2fold up- or down-regulation using a single microarray $(9,24)$. In contrast, com parative studies using macroarrays are subject to larger experimental variations. Consequently, pooling data from replicate experiments is needed to reduce the effects of these variations (21).

To compare multiple sets of gene expression data, nylon membranes are often reused. This requires an effective membrane-stripping protocol, which often includes boiling the membrane in an SDS solution. This procedure limits the reuse to five times because of physical damage to the membrane and a reduction of spotted cDNA on the membrane (BD Biosciences Clontech Atlas ${ }^{\mathrm{TM}}$ cDNA Expression Arrays User Manual). To minimize the deterioration during the dehybridization process, a gentler stripping protocol is needed. We applied a commercially available, effective, and gentle stripping method in conjunction with phosphorothioate-modified cDNA, which can be cleaved by oxidizing agents such as iodine $(8,13)$. Because of the lower melting temperature of the shorter cDNA strands, after oxidative breakdown, stripping can be carried out at relatively low temperatures, thereby reducing heat-induced damage.

As a result, we were able to perform repetitive experiments with the same set of membranes, and we show that the averaging of expression data per gene leads to a higher statistical significance of the gene expression data obtained. Previously, the limits for a reliable quantification had not been fully established for nylon membranes. Here we demonstrate how to analyze multiple macroarray experiments and to correct for experimental variations. Furthermore, we show by statistical analysis 
that by using a set of four nylon mem branes in duplicate, a 2-fold or more upor down-regulation can be accurately determined. We present our protocol by comparing gene expression between dividing and resting human umbilical vein endothelial cells (HUVECs).

\section{MATERIALS AND METHODS}

\section{Cell Culture}

HUVECs were obtained by a standard protocol as previously described (22). Cells were cultured in M199 medium (Invitrogen, Breda, The Netherlands) supplemented with $10 \%$ human serum (Invitrogen), 10\% FCS (Invitrogen), $5 \mathrm{U} / \mathrm{mL}$ heparin sodium salt (VU medical center, Amsterdam, The Netherlands), 2 mM L-glutamine (ICN Biomedicals, Zoetermeer, The Netherlands), $200 \mathrm{IU} / \mathrm{mL}$ penicillin, and 200 $\mu \mathrm{g} / \mathrm{mL}$ streptomycin (both from VU medical center) in fibronectin-coated culture flasks at $37^{\circ} \mathrm{C}$ in a humidified incubator with a $5 \% \mathrm{CO}_{2}$ atmosphere. Experiments were carried out after three passages. The HUVECs were harvested by trypsinization, washed with ice-cold PBS, and the cell pellet was frozen im mediately in liquid nitrogen and stored at $-80^{\circ} \mathrm{C}$ until RNA isolation. MCF-7 human breast cancer cells were cultured in DMEM (BioWhittaker Europe, Verviers, Belgium), supplemented with 7.5\% FCS. RNA isolated from a mixture of breast cancer cell lines and used as a common reference sample (14) was kindly provided by Dr. C. Perou (Stanford University, Stanford, CA, USA).

\section{RNA Isolation}

RNAzol-B (Campro Scientific, Veenendaal, The Netherlands) was used for the isolation of total RNA, according to the manufacturer's recommendations. The RNA pellet was dissolved in DEPC-treated water (Research Genetics, Huntsville, AL, USA) to a final concentration of at least $2.5 \mu \mathrm{g} / \mu \mathrm{L}$. The concentration was determined using spectrophotometry, with absorbance at $260 \mathrm{~nm}$. The quality of the RNA was determined by measuring the $A_{260 / 280}$ ratio and by agarose gel electrophoresis and was stored at $-80^{\circ} \mathrm{C}$.

\section{cDNA Synthesis}

For the preparation of strippable cDNA probes, we used the Strip-EZ ${ }^{\mathrm{TM}}$ RT kit (Ambion, Austin, TX, USA). Five micrograms $(2 \mu \mathrm{L})$ of total RNA were mixed with $2 \mu \mathrm{L}$ oligo(dT) (Am bion), incubated for $5 \mathrm{~min}$ at $65^{\circ} \mathrm{C}$, and allowed to cool to room temperature for 5 min. We then added $2 \mu \mathrm{L}$ reverse transcriptase buffer (Invitrogen), $2 \mu \mathrm{L}$ $10 \times$ dNTP (Ambion), $3 \mu \mathrm{L} \alpha\left[{ }^{33} \mathrm{P}\right]$ dATP (approximately $30 \mu \mathrm{Ci}$; specific activity > $2500 \mathrm{Ci} / \mathrm{mmol}$ ) (Amersham Biosciences, Roosendaal, The Netherlands), 300 U SUPERSCRIPT ${ }^{\mathrm{TM}}$ II (Invitrogen), and Superase RNase inhibitor ( $1 \mu \mathrm{L}$; Ambion). DEPC-treated water was added to obtain a total reaction volume of $20 \mu \mathrm{L}$. After mixing, the sample was incubated at $41^{\circ} \mathrm{C}$ for $1 \mathrm{~h}$. The labeled cDNA was purified using the QIAquick $^{\mathrm{TM}}$ PCR purification kit (Westburg BV, Leusden, The Netherlands). As a modification to the manufacturer's protocol, the cDNA was washed four times with $300 \mu \mathrm{L}$ PE buffer and eluted twice with $75 \mu \mathrm{L}$ EB buffer (10 mM Tris-HCl, pH 8.0). Thereafter, $6 \mu \mathrm{L} 0.5 \mathrm{M}$ EDTA, $\mathrm{pH}$ 8.0, were added to $150 \mu \mathrm{L}$ eluate. To denature the cDNA, the solution was boiled for $10 \mathrm{~min}$ and subsequently cooled on ice for $5 \mathrm{~min}$ before hybridization.

\section{Array and Hybridization}

We used the Human Atlas Cancer 1.2 array (BD Biosciences Clontech, Palo Alto, CA, USA), which includes 1176 human cDNA fragments (obtained by PCR) of cancer-related genes, nine housekeeping genes and negative controls, with a length of 200-600 bp. After stripping, the membranes were washed at $65^{\circ} \mathrm{C}$ with $10 \mathrm{~mL}$ hybridization buffer containing $6 \times \mathrm{SSC}, 0.2 \% \mathrm{SDS}$, and $5 \times$ Denhardt's reagent, $\mathrm{pH}$ 7.0. Subsequently, the membranes were prehybridized for $4 \mathrm{~h}$ at $65^{\circ} \mathrm{C}$ in a hybridization oven (model HIR12; Grant Instruments, Cambridge, UK) with $6 \mathrm{~mL}$ hybridization buffer containing $1 \mu \mathrm{g} / \mathrm{mL}$ heat-denatured Cot DNA (Invitrogen) and 100 $\mu \mathrm{g} / \mathrm{mL}$ heat-denatured salmon sperm DNA (Roche Diagnostics, Almere, The Netherlands). After hybridization, the membranes were washed twice in $0.5 \times$ $\mathrm{SSC} / 0.5 \% \mathrm{SDS}$ at $65^{\circ} \mathrm{C}$ for $3 \mathrm{~min}$, washed twice for $15 \mathrm{~min}$, and then twice in $0.2 \times \mathrm{SSC} / 0.5 \% \mathrm{SDS}$ at $65^{\circ} \mathrm{C}$ for 15 $\min$. The membranes were stored wet in $0.2 \times \mathrm{SSC} / 0.5 \% \mathrm{SDS}$ in a sealed plastic bag and exposed to a PhosphorImager ${ }^{\circledR}$ screen (model 425; Amersham Biosciences) for four days.

\section{Stripping}

Before beginning a new hybridization, membranes were stripped using the Strip-EZ method, according to the manufacturer's recommendations but with slight modifications. Membranes were incubated for $5 \mathrm{~min}$ at room temperature in $15 \mathrm{~mL}$ probe degradation buffer while gently but continuously shaking. Subsequently, the membranes were placed into hybridization bottles containing 30 $\mathrm{mL}$ reconstitution buffer and incubated in the hybridization oven at $68^{\circ} \mathrm{C}$ for 15 min. The last step was repeated once. The membranes were reused or stored in $0.5 \times \mathrm{SSC} / 0.5 \% \mathrm{SDS}$ at $-20^{\circ} \mathrm{C}$.

\section{Image Analysis}

After four days of exposure, the screens were scanned with the PhosphorImager at a resolution of $88 \mu \mathrm{m}$. Using the ImageQuant ${ }^{\mathrm{TM}}$ software (version 5.1; Amersham Biosciences), a gel-type file was obtained (square root encoded). This file was converted into two linear 16-bit TIFF files using the linear-conversion program Linconv (kindly provided by Bob Loder, Amersham Biosciences). The spot intensities were quantified using the program ScanAlyze (version 2.44; written by Michael Eisen and available from http://rana.lbl.gov). The data files obtained by ScanAlyze were imported into Microsoft ${ }^{\circledR}$ Excel $^{\circledR} 97$ and analyzed. Spots with a mean intensity of greater than 1.2 times the mean local background intensity were further considered as "measurable spots".

\section{RESULTS AND DISCUSSION}

\section{Repetitive Hybridizations}

To compare multiple sets of macroarray data, we first attempted to increase the lifespan of the nylon membranes. We used total RNA samples 
obtained from breast cancer cell lines and endothelial cells under various conditions for the multiple hybridizations of the membranes. Figure 1A shows representative images of membranes at various stages of their use and reuse to detect mRNA expression. When the stripping of the membranes continued, a considerable reduction in the signalto-background ratio was observed after using the membranes more than 10 times $(n>10)$. Figure 1A (right image) shows the increased background signal at the same signal intensity. In addition, mechanical damage caused by the handling of the membranes was observed, which was visible from black smears across the membrane surface. Signalto-noise ratios, averaged over all spots, are represented in Figure 1B. When all spots would be filled with background, the ratio would be unity (Figure 1B, broken line). A reduction in these ratios indicated the deterioration of the membrane $(n>10)$. The reproducibility of the comparisons of hybridized mem branes was expressed as a standard deviation of the noise.

This meant a considerable increase in the lifespan of the nylon membranes over conventional stripping $(n<5)$. Moreover, it offered more possibilities of obtaining accurate data by averaging the data obtained from multiple com parisons. For the spots that could be measured after hybridization, following the stripping of the membranes, the average remaining radioactivity of the cDNA per spot was $0.6 \% \pm 0.5(\bar{x} \pm \mathrm{SD}$; 261 spots). The spots that could not be measured after the initial hybridization were not included. Using this approach, the interference of the remaining signal after stripping was minimized for the next hybridization experiment.

\section{Data Analysis}

The signal intensities (minus background) on the membranes were plotted against each other for each cDNA fragment in a double logarithmic plot (Figure 2A). A double logarithmic plot has several advantages over a linear plot. First, a wide range of spot intensities can be evenly distributed along the axes, which provide a clearer overview of the data points. In addition, a sym metrical distribution of distances to- ward a trend line can be obtained in the following way. The ratio of gene expression $\mathrm{Y} / \mathrm{X}$ is defined as the ratio of the spot intensities for the same cDNA of two membranes, Y and X. The logarithm of this ratio is then:

$$
\log (\mathrm{Y} / \mathrm{X})=\log \mathrm{Y}-\log \mathrm{X}
$$

However, if two membranes have different overall intensities (because of differences in the total RNA concentration or incorporation of the label), then the ratio $\mathrm{Y} / \mathrm{X}$ needs to be normalized. The trend line is shifted up or down by $b$ (Figure 2C) until $\mathrm{Y}=\mathrm{X}$. This means that for a point $\mathrm{A}$ (Figure 2C):

$$
\log \mathrm{Y}=\log \mathrm{X}+a+b
$$

where $a$ represents the (vertical) distance of point A to the trend line. The sign of $a$ can also be negative (i.e., when $A$ is below the trend line). Please note that $a$ represents a distance and not a slope. Thus, variations in both $\log \mathrm{Y}$ and $\log \mathrm{X}$ will both contribute to variations in $a$.

Combining Equations 1 and 2 yields

$$
\log (\mathrm{Y} / \mathrm{X})=a+b \quad \text { [Eq. 3] }
$$

Thus, for each gene, $a$ can be found by subtracting $b$ from $\log (\mathrm{Y} / \mathrm{X})$. This means that the spot intensities between the two membranes $\mathrm{X}$ and $\mathrm{Y}$ are significantly different when $a$ is different from zero (i.e., A does not lie on the trend line). Therefore, when comparing two different samples, it can be concluded that a certain gene is significantly up- or down-regulated if $a$ (Figure $2 \mathrm{C}$ ) is different from zero. Along the same lines, considering $\log (\mathrm{X} / \mathrm{Y})$ instead of $\log (\mathrm{Y} / \mathrm{X})$ would lead to the horizontal distance to the trend line.

If the same samples are compared (self-self comparison), then, $a$ should ideally be zero. However, fluctuations from many sources (20) will lead to noise. This means that A will scatter around the trend line. For most individual genes, $a$ will not be zero but will have a positive or negative value. A histogram of the distances to the trend line showed a normal distribution (Figure 2D). The standard deviation of the corresponding Gaussian curve is an important parameter de-

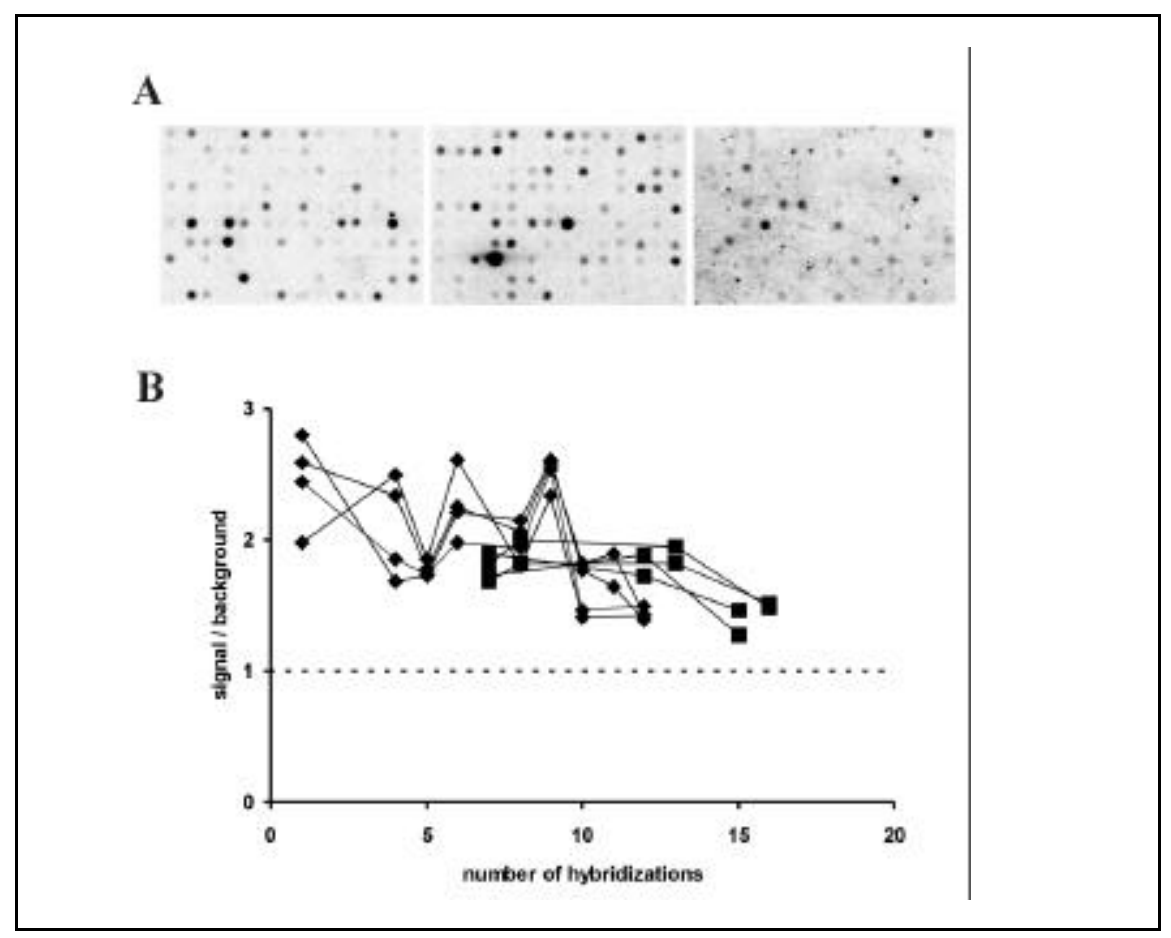

Figure 1. Decrease in signal-to-background ratio after repetitive stripping and hybridization. (A) Representative parts of nylon membranes (Atlas Cancer 1.2 arrays) after hybridization to ${ }^{33} \mathrm{P}$-labeled cDNA, showing the increase of the background noise after using the membranes more than 10 times. Left, first use of unstripped membranes $(n=1)$; middle, after stripping nine times $(n=10)$; and right, after stripping 15 times $(n=16)$. (B) Signal-to-background ratios averaged over all spots at different hybridization numbers for two sets of membranes (represented by diamonds and squares, respectively). Only background noise without a signal would result in a ratio of unity (broken line). 
scribing the noise of the method. To characterize this noise, 13 self-self comparisons were studied (mRNA was obtained from breast cancer cell lines and endothelial cells under various conditions). The mean standard deviation of $a$ for these 13 comparisons was $0.59 \pm 0.13$. Some comparisons consist of more measurable spots than others. All individual values of $a$ were used to calculate a progressive mean as well. For each point, 100 extra values of $a$ were added, and the standard deviation was calculated for the cumulative population of values for $a$ (Figure 3A). The progressive mean of the standard deviation approached a constant value of $\left(\log _{2}=\right.$ 0.57) (Figure 3A). The histogram of all values of $a$ is represented in Figure 3B. To monitor the effect of repetitive hybridizations on the noise, the standard deviation was plotted against the number of hybridizations (Figure 3C). Please note that each point represents a comparison between two mem branes. The data point at 8.5 arises because one membrane had been used eight times and the other nine times. The data point at 10.5 arises for a similar reason. No significant increase in the standard deviation was observed in the range $n=1-10$.

For a normal distribution, the chance that in a self-self comparison a false positive will be found beyond 1.96 times the standard deviation from the mean is $5 \%$ (2). Because we found the standard deviation to be 0.57 , this means that for any comparison, $5 \%$ of the genes with $a=1.1$ (or -1.1) are falsely designated to be up- or downregulated by a factor $2.1\left(\log _{2} 2.1=\right.$ 1.1). To increase the accuracy of the measurement, we used replicate experiments for averaging the distance $a$ per gene. After averaging two distances $a$ per cDNA fragment, a progressive mean of $\log _{2}=0.39$ was obtained (Figure 3A). This means that the error in establishing up- or down-regulation by a factor of two was reduced from $5 \%$ to
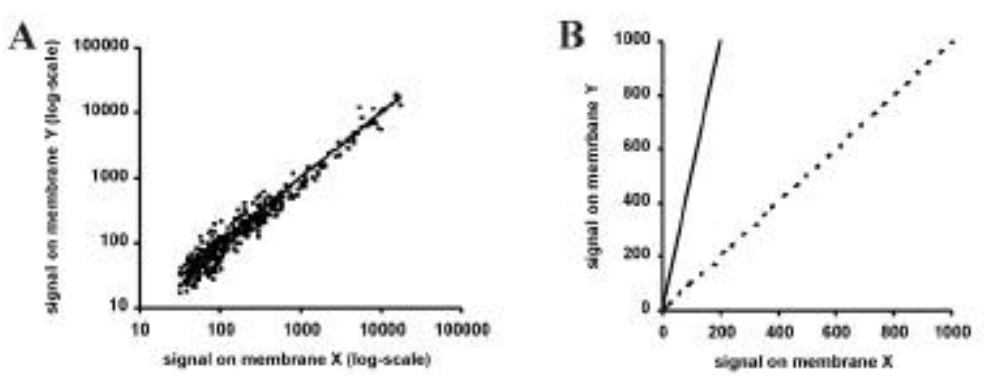

C
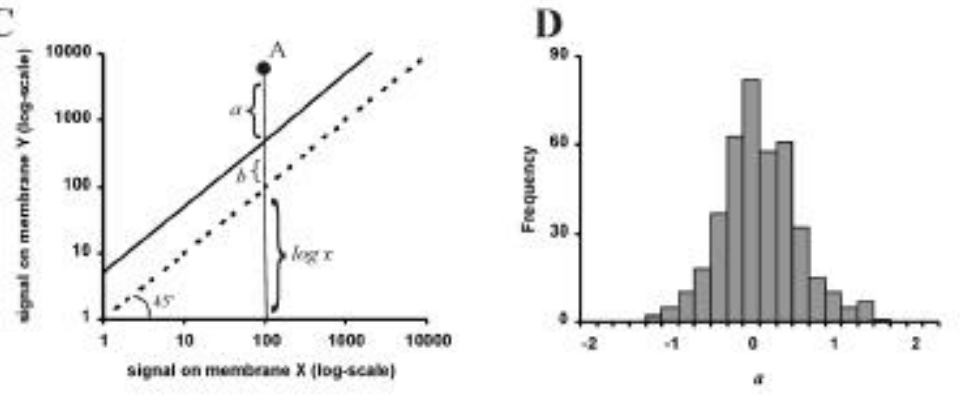

Figure 2. Schematic outline of data analysis. (A) Double logarithmic plot of spot intensities after hybridizing identical samples (mRNA from the Stanford breast cancer common reference), which is referred to as self-self comparison in the text. (B) Theoretical double linear plot of spot intensities. The broken line $\mathrm{Y}=\mathrm{X}$ represents equal spot intensities on both membranes (as would be found in an ideal self-self comparison without noise), and the drawn line shows higher intensities for $\mathrm{Y}$ by a constant factor. (C) Both lines are parallel in a double logarithmic plot with an angle of $45^{\circ}$, and the overall difference between the two membranes is represented by $b$, which equals the mean $\log (\mathrm{Y} / \mathrm{X})$. We normalize our experimental values by subtracting $b$ from the individual $\log (\mathrm{Y} / \mathrm{X})$ for each gene. The vertical distance of point A to the trend line is represented by $a$. If $a$ is significantly different from zero, then A is not on the trend line and represents a differentially expressed gene. (D) A histogram of the distribution of the distances $a$ around the average ratio for the data of A.

$1 \%$ (from 1.96 to $2.5 \mathrm{SD}$, respectively). We obtained an SD of 0.26 and a corresponding further reduction of the error to less than $0.1 \%$ for measuring up- or down-regulation by a factor of two by averaging four distances $a$ per gene (2). A 2-fold change in gene expression is also considered as the detection limit for microarrays on glass slides (9).

It is expected that the standard deviation of the mean of $n$ independent com parisons will decrease by $\vee n$ (11). Indeed, this is what we observed when comparing the progressive means for one, two, and four replicate experiments (Figure 3A). To minimize the effect of differences in spotted cDNA fragments further, we switched the probes used among membranes in replicate experiments. We performed this test three times and found an average reduction in the standard deviation of $22 \%$. This result illustrates the effect of differences in cDNA content on different mem branes of the same batch. Although this is a minor effect in relation to the increase of the $n$, it results in an extra reduction in the standard deviation simply by swapping the membranes. We also compared the same membranes hybridized on different days and different membranes hybridized on the same day (in triplicate). No significant difference in the mean standard deviation was found. Although variations in the amount of spotted cDNA fragments are minimized when comparing the same membrane, differences in probe labeling and hybridization circumstances may account for the relatively larger variations between days.

The highest variation in signal was found for the spots with the lowest intensities. However, adherence to our established exclusion criterion for spots with intensities lower than $20 \%$ of the local background excluded those spots from further consideration. Others have used amplification to increase the concentration of mRNA species with low prevalence in the probe to be able to detect them reliably (16). The population of measurable spots showed a fairly constant standard deviation. Typically, the maximum variation in the standard deviation was on the order of $20 \%$. Routinely, the number of measurable spots was $20 \%-35 \%$ of all the spots on the membrane. 
Table 1. Scheme of Duplicate Macroarray Experiments Using Four Nylon Membranes

\begin{tabular}{|ccccc|}
\hline Experiment & A & B & C & D \\
\hline I & 2 & 1 & 2 & 1 \\
II & 1 & 2 & 1 & 2 \\
For both experiments, it is indicated which sample (1 or 2) was hybridized to \\
which membrane (A-D). Sample 1 contained cDNA from growing HUVECs, \\
and sample 2 contained cDNA from confluent cells.
\end{tabular}
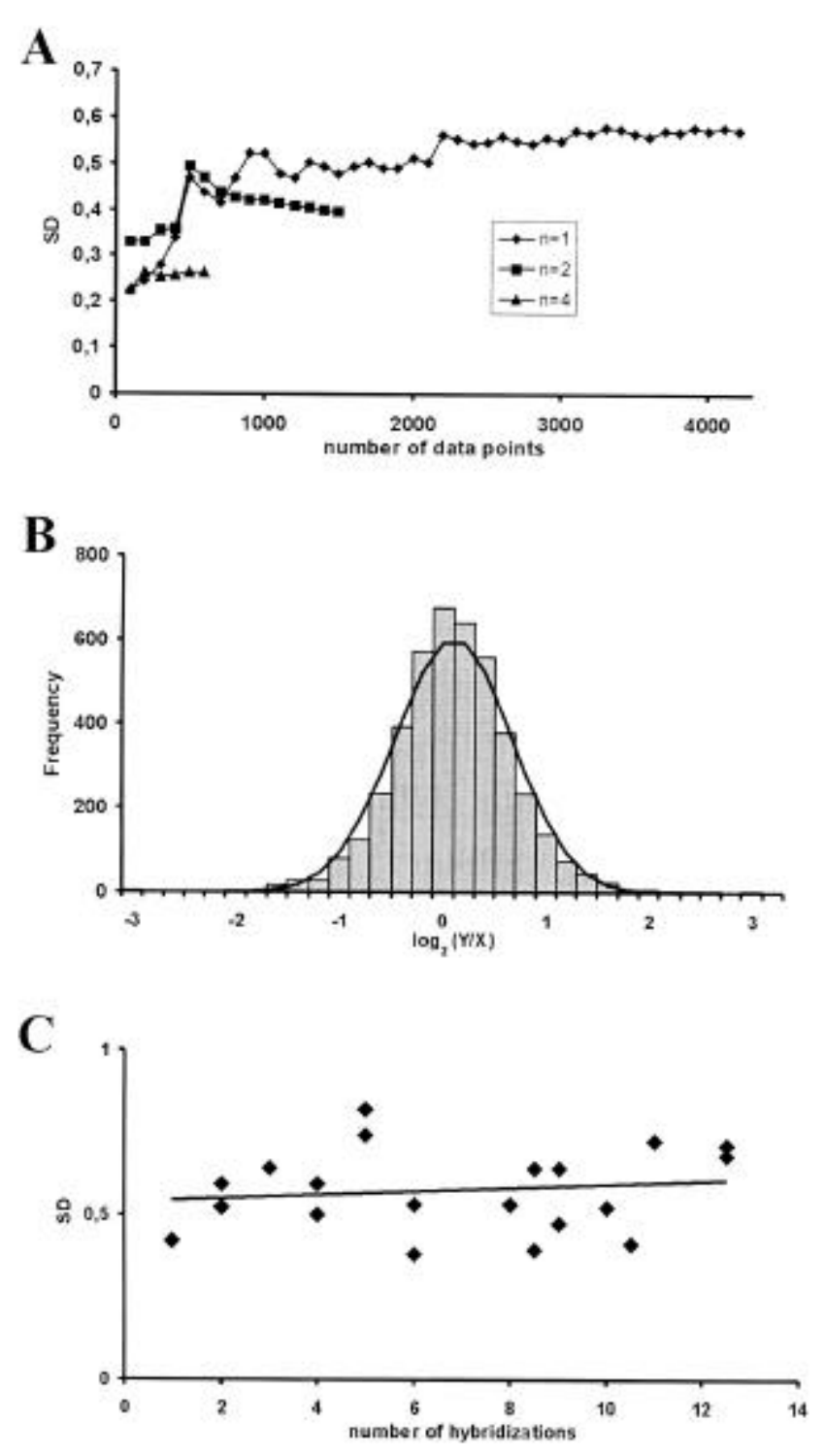

Figure 3. Comparison of identical samples hybridized on two membranes. (A) Progressive mean of the standard deviation (SD) of the distances $a$ after each subsequent addition of 100 distances. Twentysix data sets were used for 13 self-self comparisons, yielding 4290 data points $(n=1)$. The progressive mean standard deviation decreased after averaging $a$ from two replicate experiments $(n=2)$ from 0.57 to 0.39 and further for four replicate experiments $(n=4)$ from 0.39 to $0.26\left(\log _{2}\right)$. (B) A histogram is presented for all data points before averaging $(n=1)$ (i.e., vertical distances $a$ to the trend line). (C) The standard deviation for 20 self-self comparisons at various stages of reuse of the membranes (data of four sets of membranes). Note that at dissimilar numbers of previous hybridizations of individual membranes, the average number in the comparison may not be an integer.

\section{Application}

To examine the effect of averaging replicate experiments and the practice of reversing membranes, we applied the analytical method described above to identify differentially expressed genes among growing and confluent HUVECs. Confluency has been shown to cause endothelial cells to inactivate mitotic signaling (23). Therefore, we reasoned that the expression levels of several cell cycle-related genes would be influenced by confluency. Cells were harvested at approximately $30 \%$ confluency (Table 1, sample 1) or two days after reaching confluency (Table 1, sample 2). Because replicate experiments are statistically advantageous, we hybridized these samples to a set of four membranes in two successive experiments.

Initially, the noise under the experimental conditions was determined in one experiment on the same day by comparing the same samples. The distances $a$ to the trend line (see Figure 2C) from experiment I (Table $1, \mathrm{~A} / \mathrm{C}$ and $\mathrm{B} / \mathrm{D})$ were averaged per gene. The resulting SD $(n=2)$ was $0.66\left(\log _{2}\right)$. Subsequently, the averaging was carried out after membrane reversal [e.g., for $\mathrm{A} / \mathrm{C}$ (experiment I) and C/A (experiment II)]. This resulted in an SD of 0.45 , which further demonstrates that reversing mem branes during the experiments increases the statistical significance of the data. When the distances $a$ from all four com parisons were averaged per gene, we obtained an SD of $0.28\left(\log _{2}\right)$. Up- or down-regulation by a factor of two corresponds to 3.6 times standard deviation; indeed, we did not detect such false positives at or beyond this level. Thus, in this experiment, up- or down-regulation by a factor of two can be determined within an error of less than $0.1 \%$.

At a significance level of $0.3 \%$ (corresponding to 2.97 times standard deviation), we found 9,12 , and 47 differentially expressed genes in growing versus confluent HUVECs for $n=1,2$, and 4, respectively. This can be attributed to the reduction of experimental noise by averaging replicate experiments and reversing membranes. Among these 47 genes $(n=4)$, we identified known cell cycle-related genes such as cyclins B1, $\mathrm{E}$, and $\mathrm{H}$, which were found to be 
down-regulated as a result of confluency. Further studies on the cell biology of endothelial cells are warranted.

Here we have focused on self-self comparisons. The statistical data presented demonstrate that the measurement of up- or down-regulation by a factor of two or more can be accurately measured by hybridization on nylon membranes when replicate experiments are averaged.

\section{ACKNOWLEDGMENTS}

Dr. W.P.H. de Boer is gratefully acknowledged for the statistical advice. The authors are indebted to Dr. C. Löwik for suggesting the stripping method and to Dr. S. Spijker for advice on the hybridization conditions. The authors thank A. Krielen for skillful data processing and Dr. H.V. Westerhoff for inspiring discussions. We thank N. Brady for critically reading the manuscript. J.J.H. and R.R.H. contributed equally to this work.

\section{REFERENCES}

1.Alizadeh, A.A., M.B. Eisen, R.E. Davis, C. Ma, I.S. Lossos, A. Rosenwald, J.C. Boldrick, H. Sabet, et al. 2000. Distinct types of diffuse large B-cell lymphoma identified by gene expression profiling. Nature 403:503-511.

2.Altman, D.G. 1994. Practical Statistics for Medical Research, p. 194, Chapman \& Hall, London.

3.Bertucci, F., K. Bernard, B. Loriod, Y.C. Chang, S. Granjeaud, D. Birnbaum, C. Nguyen, K. Peck, et al. 1999. Sensitivity issues in DNA array-based expression measurements and performance of nylon microarrays for small samples. Hum. Mol. Genet. 8:17151722.

4.Bittner, M., P. Meltzer, Y. Chen, Y. Jiang, E. Seftor, M. Hendrix, M. Radmacher, R. Simon, et al. 2000. Molecular classification of cutaneous malignant melanoma by gene expression profiling. Nature 406:536-540.

5.Chalifour, L.E., R. Fahmy, E.L. Holder, E.W. Hutchinson, C.K. Osterland, H.M. Schipper, and E. Wang. 1994. A method for analysis of gene expression patterns. Anal. Biochem. 216:299-304.

6.DeRisi, J., L. Penland, P.O. Brown, M.L. Bittner, P.S. Meltzer, M. Ray, Y. Chen, Y.A. Su, et al. 1996. Use of a cDNA microarray to analyze gene expression patterns in human cancer. Nat. Genet. 14:457-460.

7.Gerhold, D., T. Rushmore, and C.T. Caskey. 1999. DNA chips: promising toys have become powerful tools. Trends Biochem. Sci.
24:168-173.

8.Gish, G. and F. Eckstein. 1988. DNA and RNA sequence determination based on phosphorothioate chemistry. Science 240:15201522.

9.Hughes, T.R., M.J. Marton, A.R. Jones, C. Roberts, R. Stoughton, C.D. Armour, H.A. Bennet, E. Coffey, et al. 2000. Functional discovery via a compendium of expression profiles. Cell 102:109-126.

10.Iyer, V.R., M.B. Eisen, D.T. Ross, G. Schuler, T. Moore, J.C.F. Lee, J.M. Trent, L.M. Staudt, et al. 1999. The transcriptional program in the response of human fibroblasts to serum. Science 283:83-87.

11.Kreyszig, E. 1979. Introductory Mathematical Statistics, p. 173-175. John Wiley \& Sons, New York.

12.Kudoh, K., M. Ramanna, R. Ravatn, A.G. Elkahloun, M.L. Bittner, P.S. Meltzer, J.M. Trent, W.S. Dalton, et al. 2000. Monitoring the expression profiles of doxorubicin-induced and doxorubicin-resistant cancer cells by cDNA microarray. Cancer Res. 60:41614166.

13.Mag, M., S. Lüking, and J.W. Engels. 1991. Synthesis and selective cleavage of an oligodeoxynucleotide containing a bridged internucleotide 5'-phosphorothiorate linkage. Nucleic Acids Res. 19:1437-1441.

14.Perou, C.M., T. Sorlie, M.B. Eisen, M. van de Rijn, S.S. Jeffrey, C.A. Rees, J.R. Pollack, D.T. Ross, et al. 2000. Molecular portraits of human breast tumors. Nature 406:747-752

15.Ramsay, G. 1998. DNA chips: state-of-theart. Nat. Biotechnol. 16:40-44.

16.Rast, J.P., G. Amore, C. Calestani, C.B. Livi, A. Ransick, and E.H. Davidson. 2000. Recovery of developmentally defined gene sets from high-density cDNA macroarrays. Dev. Biol. 228:270-286.

17.Rinehart-Kim, J., M. Johnston, M. Birrer, and T. Bos. 2000. Alterations in the gene expression profile of MCF-7 breast tumor cells in response to c-Jun. Int. J. Cancer 88:180190.

18. Ross, D.T., U. Scherf, M.B. Eisen, C.M. Perou, C. Rees, P. Spellman, V. Iyer, S.S. Jeffrey, et al. 2000. Systematic variation in gene expression patterns in human cancer cell lines. Nat. Genet. 24:227-235.

19.Scherf, U., D.T. Ross, M. Waltham, L.H. Smith, J.K. Lee, L. Tanabe, K.W. Kohn, W.C. Reinhold, et al. 2000. A gene expression database for the molecular pharmacology of cancer. Nat. Genet. 24:236-244.

20.Schuchhardt, J., D. Beule, A. Malik, E. Wolski, H. Eickhoff, H. Lehrach, and $H$. Herzel. 2000. Normalization strategies for cDNA microarrays. Nucleic Acids Res. 28:E47.

21.Ting Lee, M.-L., M.L. Lee, F.C. Kuo, G.A. Whitmore, and J. Sklar. 2000. Importance of replication in microarray gene expression studies: statistical methods and evidence from repetitive cDNA hybridizations. Proc. Natl. Acad. Sci. USA 97:9834-9839.

22.Van Hinsbergh, V.W.M. and R. Draijer. 1996. In vitro models and functional studies of endothelium. Culture, characterization, and application of human endothelial cells, p.87.
In A.J. Shaw (Ed.), Cell Culture Models of Epithelial Tissues. A Practical Approach. Oxford University Press, Oxford.

23.Vinals, F. and J. Pouyssegur. 1999. Confluence of vascular endothelial cells induces cell cycle exit by inhibiting p42/p44 mitogen-activated protein kinase activity. Mol. Cell. Biol. 19:2763-2772.

24. Yue, H., P.S. Eastman, B.B. Wang, J. Minor, M.H. Doctolero, R.L. Nuttall, R. Stack, J.W. Becker, et al. 2001. Nucleic Acids Res. 29:E41-1.

Received 28 August 2001; accepted 1 February 2002.

Address correspondence to:

Prof. Jan Lankelma

$V U$ medical center

Department of Medical Oncology, BR230

De Boelelaan 1117

1081 HV Amsterdam, The Netherlands

e-mail: j.lankelma@vumc.nl

For reprints of this or any other article, contact Reprints@BioTechniques.com 